\title{
Future environmental and geographic risks of Fusarium head blight of wheat in Scotland
}

\author{
Peter Skelsey • Adrian C. Newton
}

Accepted: 20 January 2015 / Published online: 7 February 2015

C The Author(s) 2015. This article is published with open access at Springerlink.com

\begin{abstract}
Methods used to assess climate change risk for crop diseases often assume that both host and pathogen are present. Consequently, model output may misrepresent future growing seasons, due to a failure to reflect likely change at the landscape- and farm-scale and its impact on disease risk. In this study, data defining the spatial coverage of crops in Scotland were combined with spatially coherent, probabilistic climate change data to project the future risk of Fusarium head blight (FHB) in wheat. Primary inoculum was initially treated as non-limiting, and a widely accepted crop-diseaseclimate model for FHB risk assessment was used to project the risk of disease occurrence in over 50,000 crop locations. Primary inoculum was then treated as limiting, and an atmospheric dispersion model was used to modify projections according to the risk of inoculum dispersal from overwintering refugia to crop locations. In both cases it was predicted that FHB hazard will decrease in Scotland over time. Consequences for the species composition of the FHB complex and therefore the associated mycotoxin hazard were considered. To guide adaptation strategies, we also considered agronomic scenarios regarding potential climate-changedriven shifts in agricultural practices and planting patterns, and their effects on disease risk. We found that opportunities exist for increased cultivation of crops that are potent sources of Fusarium or Gibberella inoculum, and for movement of crops away from coastal areas
\end{abstract}

P. Skelsey $(\bowtie) \cdot$ A. C. Newton

The James Hutton Institute,

Invergowrie, Dundee DD2 5DA, UK

e-mail: peter.skelsey@hutton.ac.uk vulnerable to sea-level rise, with little additional risk of FHB. These projections, made by considering the temporal and spatial coincidence of host and pathogen species under various climate change scenarios, suggest that improved control of FHB might not be a high priority for future food security in Scotland.

Keywords Fusarium head blight (Gibberella zeae/Fusarium culmorum) · Mycotoxins · Climate change $\cdot$ Risk assessment $\cdot$ Inoculum dispersal

\section{Introduction}

Across the world, climate change is simultaneously affecting the growth of agricultural crops and the incidence and intensity of crop disease epidemics (Chakraborty 2005; Garrett et al. 2006; Metz 2007; Stern 2007; Beddington 2010). Accordingly, there has been recent interest in combining linked models for crop growth and plant disease with climate scenarios to produce more accurate projections of the impacts of climate change on crop productivity (Fernandes et al. 2004; Gouache et al. 2007; Madgwick et al. 2011). This approach, whereby disease risk under future climates is based purely on the response of the host crop and pathogen species to weather variables, can be criticised, however, for assuming that both host and pathogen are present. That is, although crop-disease-climate models have been used to make spatial predictions (e.g., disease risk maps), they are usually developed exclusively in environmental space and not geographic space. 
Relaxing this assumption requires consideration of complexities that may lead to higher or lower levels of inoculum availability and pathogen dispersal among production areas (Garrett et al. 2011). For instance, host abundance and heterogeneity can vary over a spectrum of scales in a landscape, pathogen dispersal processes have a characteristic scale (the dispersal range of the species), and the interplay between these different scales affects the spread of disease (Skelsey et al. 2007, 2013a, b; Skelsey and Newton 2014). Thus, an agricultural landscape may have epidemic suppressive or enhancing effects that confound projections for the impact of climate on crop productivity based on weather variables alone. As a result, crop-disease-climate models may misrepresent future growing seasons. Moreover, in the future farmers may plant crops in different areas so as to avoid disease, switch to growing different crop varieties or species, or avoid cropping practices that enhance disease risk, such as growing maize in cereal-based rotations. To date, little has been done to include spatial context in projected climate change impacts on crop productivity; i.e., to account for realistic distributions of inoculum sources and host crops, and the potential for spread of disease among them. A priority now is to develop methodologies for projecting the unfolding consequences of climate change that can account for spatial processes in crop disease epidemics and climate-change-driven shifts in agricultural patterns and practices.

Fusarium head blight (FHB) is a major disease of small cereals, including wheat (Triticum aestivum L.) and barley (Hordeum vulgare L.). The disease is caused by a complex of different Fusarium and Gibberella spp. (Parry et al. 1995), although Gibberella zeae (Schwein.) Petch (syn. Fusarium graminearum) has been the major determinant in the UK over the last 10 years because its higher temperature optimum favours its dominance in the disease complex (Waalwijk et al. 2003; Jennings et al. 2004; Miedaner et al. 2008; Chakraborty and Newton 2011). Fusarium and Gibberella spp. infect cereal spikes during flowering and colonise the developing kernels. Additionally, they produce mycotoxins that can be present in both grain and straw at harvest that are problematic for production processes and hazardous to human and animal health at high concentrations (McMullen et al. 1997; Salas et al. 1999; Desjardins and Proctor 2007; Edwards 2011). Contamination of wheat by Fusarium and Gibberella mycotoxins is now one of the top food safety concerns associated with a changing climate in Europe (Miraglia et al. 2009). This is because wheat is the most economically-important small grain cereal world-wide and is the most susceptible to FHB and mycotoxin contamination in many countries (Edwards 2007); the incidence and concentration of most mycotoxins have remained relatively low in other cereals, such as barley and oats, compared to values for wheat (Jones and Mirocha 1999; Campbell et al. 2002; Langevin et al. 2004; Edwards 2007, 2011, 2012). European Commission (EC) legislative limits for the mycotoxins deoxynivalenol (DON) and zearalenone (ZON) were introduced in 2006 for cereals and cereal products for human consumption (Edwards 2011). Guideline limits were also set for animal feed in the same year.

Risk assessment models in current use for predicting FHB epidemics and/or resulting mycotoxin contamination in wheat are based on the environmental niche (effects of local weather on crop growth and wheat infection) and neglect spatial processes (Hooker et al. 2002; De Wolf et al. 2003; Madgwick et al. 2011; HGCA 2012; Xu et al. 2013). The disease is primarily monocyclic (secondary infection is rare), and inoculum deposited on wheat spikes may have been transported by wind and turbulence some distance from its source (Maldonado-Ramirez et al. 2005). G. zeae overwinters in residues of wheat, barley, oats and other small cereal grains and maize (Zea mays or corn). In the following spring and summer both sexual spores (ascospores) and asexual spores (conidia) are produced. Although both spores contribute to the disease propagation, ascospores that are forcibly discharged into the air from mature fruiting bodies (perithecia) serve as the primary inocula for FHB epidemics in cereal crops (Trail et al. 2002; Schmale et al. 2005). The ascospores rely on wind and turbulence for transport to wheat production areas, and rain for splash dispersal up the plant stem and leaves onto the emerging heads of wheat where they cause FHB on susceptible crop varieties (Schmale III and Bergstrom 2003; Shaner 2003). Unfortunately, the aerobiology of $G$. zeae is poorly understood and little is known about how far the inoculum travels. The bulk of the literature suggests that most ascospores are dispersed only a short distance from a source though this assumption has not been validated. In contrast, recent studies provide evidence of ascospores many kilometres from apparent inoculum sources, and high in the planetary boundary layer (Francl et al. 1999; MaldonadoRamírez 2001; Schmale and Bergstrom 2003; 
Maldonado-Ramirez et al. 2005). These data suggest the role of long-distance transport in regional epidemics of FHB, and the importance of considering spatial context (distributions of distant inoculum sources, wheat crops, and dispersal among them) in projected climate change impacts on the infection of wheat and contamination of wheat by Fusarium and Gibberella mycotoxins.

Using Scotland as a case study, the goals of this research were to: (i) project the future risk of FHB under the assumption that primary inoculum is not limiting (i.e., it is ubiquitous), and disease risk is dependent on the presence of the host and the effects of weather on crop growth and FHB development; (ii) project the future risk of FHB spread under the assumption that primary inoculum is limiting, and disease risk is dependent on transmission of primary inoculum from overwintering refugia, the presence of the host, and the effects of weather on crop growth and subsequent FHB development; and (iii) evaluate agronomic scenarios regarding the impact of expected climate-changedriven shifts in cultivation practices and planting patterns on FHB risk. As under current cropping practices, wheat residues are the main source for inoculum of mycotoxin producing Fusarium or Gibberella chemotypes (Khonga and Sutton 1988; Edwards 2007, 2011, 2012; Slaiding and Byrd 2013; Xu et al. 2013), we discounted alternative host species and utilised data on the spatial coverage of wheat crops in our climatic risk assessments. We focused on Scotland as our study area due to the strategic importance of wheat to the Scottish economy, e.g., for grain whisky production (Chakraborty and Newton 2011; Scottish Government 2012), and because FHB has recently been identified as a potential future threat to Scottish wheat production (SRUC 2013). We used a widely accepted crop-diseaseclimate model considered as 'best practice' for projecting the risk of FHB occurrence in wheat in the UK ("Risk assessment for Fusarium mycotoxins in wheat," HGCA Topic Sheet 114, www.hgca.com). For transport of inoculum we used an atmospheric dispersion model from the meteorological sciences (Skelsey et al. 2010). It should be noted that forecasting FHB disease development and mycotoxin contamination are regarded as two separate but related exercises (Kriss et al. 2012; Landschoot et al. 2012), and our primary objective here is in using the former to demonstrate the utility of spatial context in climatic risk assessments for crop diseases. We do, however, discuss the likely correlative mycotoxin contamination of wheat under future climates.

\section{Materials and methods}

All operations described in the following sections were conducted in the Matlab numerical computing environment (Mathworks, Natick, MA, USA, version 7.14) using standard commands from the mapping toolbox, and were performed on a Dell Precision T7500 with dual Intel Xeon E5645 (Six Core, $2.4 \mathrm{GHz}$ ) processors and 48GB RAM on a 64-bit Windows platform.

\section{Crop distribution data}

Many results from recent studies suggest that climate change in Scotland needs to be larger than projected over the next century to be a major factor in modifying agriculture (Kerr et al. 1999; Hay et al. 2000; DEFRA 2012). For this reason we initially proceed under the assumption that the current spatial coverage of winter wheat crops provides a proxy indicator of future coverage (we later relax this assumption in a number of agronomic scenarios). Annual data defining the spatial coverage of winter wheat crops in Scotland were derived from the Scottish Integrated Administration and Control System (IACS) (http://rpa.defra.gov.uk) and June Scottish Agricultural Census (http://www. scotland.gov.uk). These data are protected and are only available to the public in a high level summary form using the links provided. To capture variation in the distribution of crops between years, data from six different growing seasons (2006 to 2011) were used, representing approximately 10,000 wheat crops per season (59,512 locations in total). Each individual crop distribution provided a different proxy of future coverage, i.e., we considered these data as six different realisations of future crop coverage. These vector datasets were rasterised to a 30 arcsecond grid to facilitate implementation of the risk models. This resolution provided sufficient spatial detail to capture the configuration of crop distributions and was computationally tractable.

Weather data for climate change scenarios

Raw monthly $25 \mathrm{~km}$ gridded climate data (mean temperature, mean precipitation, and wind speed anomaly) 
were obtained from the UK Met Office Climate Projections database (UKCP09) 11-member ensemble of spatially coherent climate projections (SCPs). These data are freely available for download at http:// ukclimateprojections.defra.gov.uk/. Two thirty year future time-slices (2030-2059, 2070-2099) and two climate forcing scenarios (UKCP09 Low and High $\mathrm{CO}_{2}$ emissions) were used. UKCP09 1961-1991 baseline data were used for comparison, making a total of five climate change scenarios: baseline, Lo 40, Hi 40, Lo 80, Hi 80. The UKCP09 SCPs have a monthly resolution therefore a spline interpolation technique was used to downscale temperature and precipitation data to a daily temporal resolution comparable with the requirements of the FHB disease risk model (Press et al. 1992). Monthly wind speed anomalies were added to baseline data for use in the FHB spread risk model.

Weather-based risk assessment model for FHB in wheat

The 'HGCA risk assessment for Fusarium mycotoxins in wheat' is the model most commonly adopted to help growers assess mycotoxin risk in the UK (Edwards 2013). The model is used for prediction of FHB and assumes correlative levels of mycotoxins. The current version has been validated using a number of years of UK winter wheat disease survey data (http://www. cropmonitor.co.uk/) and can accurately predict FHB contamination in approximately $70 \%$ of cases (Edwards 2011).

It is comprised of two look-up tables that assign risk scores for DON and ZON accumulation in wheat on the basis of total rainfall accumulated during two key periods of wheat growth: anthesis (GS59-GS69 on the Zadoks scale) and grain ripening (GS87 to harvest). Rainfall events during anthesis result in splash dispersal of ascospores up the plant stem and leaves and onto the wheat heads. Ascospores are assumed to be present, therefore primary inoculum is not limiting in this model. Further rainfall during ripening allows saprophytic growth on the standing crop (Edwards 2011). Time to anthesis and ripening are determined through the accumulation of thermal time (growing degree days above $0{ }^{\circ} \mathrm{C}$ ) as per the HGCA wheat growth guide (HGCA 2008). Final risk scores are then modified according to various crop factors, such as varietal resistance, cultivation, and previous crop. It is difficult to predict agronomic practices far ahead in the future (see 'Future agronomic scenarios' section) therefore we made simplifying assumptions regarding wheat cultivar and cultivation in our projections: the previous crop was not wheat or maize (typical arable rotation in Scotland), the current crop is of average susceptibility/resistance based on current HGCA Recommended List ratings (www. hgca.com), and extensive use of minimum tillage.

All output raster layers (date of onset and end of anthesis and ripening, total rainfall accumulation during anthesis and ripening periods, and FHB risk score) were re-sampled from their original cell size $\left(25 \mathrm{~km}^{2}\right)$ to match the spatial resolution of the crop distribution data using nearest neighbour assignment (to preserve integer values).

Spatially explicit, weather-based risk assessment model for spread of FHB in wheat

Whether or not primary inoculum is ubiquitous at the moment of greatest risk of ear infection (anthesis) is contentious, therefore we now relax this assumption and consider the case where primary inoculum is limiting. As wheat residues are the main source for inoculum of DON and ZON producing Fusarium and Gibberella chemotypes, wheat crop locations from the previous year were used as the primary inoculum sources in the (following) year of interest. The 'FHB spread risk' score was computed as the product: risk of primary inoculum transmission $\times$ risk of disease development; i.e., the FHB risk score at each wheat pixel was weighted according to the risk of spatial interactions with primary inoculum sources. In other words, the risk score at each wheat location was weighted by the risk, $I(-)$, of inoculum deposition on wheat at that location. This was calculated using an atmospheric dispersion model developed by meteorological sciences. Gaussian plume models are currently the most commonly used dispersion models to estimate the downwind impact of emission sources, and are well understood, easy to apply, and have received international recognition (Skelsey 2008). The particular version used here has previously been validated and used for the dispersion of Phytophthora infestans sporangia (Skelsey et al. 2010) and Leptosphaeria maculans ascospores (Zhang et al. 2014). The Gaussian plume formulae are given in Skelsey et al. (2010) and the parameterization scheme describing the effects of wind and turbulence on lateral and vertical plume spread is given in Zhang et al. (2014). As the model has been fully described in these citations, we describe only the salient points required to repeat our analyses. 
In addition to the coordinates of inoculum sources and wheat locations, the Gaussian plume model required the following input data to compute spore dispersion: wind speed, wind direction, atmospheric turbulence, 'source strength' (amount of inoculum at the source), and terminal velocity of spores (the speed at which they fall in the atmosphere, down towards the surface). In the absence of a quantitative model to predict the influence of weather on Fusarium or Gibberella inoculum production on wheat residues in the UK, we made a number of simplifying assumptions. We simulated a single (typical) springtime dispersal event using the average spring wind speeds at inoculum source locations as input for the model (Gaussian plume models use the weather conditions at the source location to compute dispersion). Wheat crop locations were considered to be directly downwind from each inoculum source at some point during springtime spore production and release, thereby eliminating the need for wind direction in the model. Spring wind speeds were moderate to strong at all wheat locations therefore the turbulent state of the atmosphere was defined as 'neutral.' The area of wheat grown in each grid cell in the previous year was used as a proxy measure for the area of crop debris, with an ascospore density of $1 \times 10^{5} \mathrm{~m}^{-2}$ debris (Prussin et al. 2014). The terminal velocity of $G$. zeae ascospores has previously been measured at $2.58 \mathrm{~mm} \mathrm{~s}^{-1}$ (Trail et al. 2005)

To compute $I$, the Gaussian plume model was used to predict the cumulative deposition (no. $\mathrm{m}^{-2}$ ) of ascospores (emanating from all inoculum sources) in each grid cell. This was then multiplied by the area of wheat in each grid cell to obtain a surface of the number of ascospores depositing on wheat areas. These values were then normalised to the maximum value attained to provide a score between 0 and 1 for the risk of primary inoculum transmission. FHB risk scores were then weighted by $I$. The resultant distribution of FHB spread risk scores provided a measure of the environmental and geographic risks of FHB; i.e., the risk of disease as a function of climate, the abundance and configuration of inoculum sources and host crops, and the ability of the pathogen to move among them.

Projected risk of FHB for the 2040s and 2080 s - primary inoculum is non-limiting

FHB risk scores were generated for each Scottish land grid cell using the UKCP09 SCPs for all five of the climate change scenarios. Projected climate change impacts on date of onset and end of anthesis and ripening, total rainfall accumulation during anthesis and ripening periods, and FHB risk scores were averaged over all land grid cells under the different climate change scenarios, and summarised using boxplots (computed from the 11-member ensemble of SCPs) to quantify uncertainty due to internal climate variation.

Scotland has three different climate regions (as defined by the UK Met Office; http://www.metoffice.gov. uk/climate/uk/regional/): Northern, Western, and Eastern Scotland. In general, places in the east and south tend to be drier, warmer, sunnier and less windy than those further west and north. Thus, there may be differences in wheat growth rates and FHB risk among the climate regions and even within the main eastern Scotland region where most of the wheat is grown as this extends from just east of Carlisle to east of Inverness. Projected climate change impacts on date of onset and end of anthesis and ripening, total rainfall accumulation during anthesis and ripening periods, and FHB risk scores for each land grid cell were averaged over northern, western, and eastern Scotland under the different climate change scenarios, in order to investigate the influence of regional climate on the various components of FHB risk. National (all Scottish land grid cells) and regional (all land grid cells within a climate region) FHB risk scores were compared to FHB risk scores averaged over all wheat grid cells in five rasterised wheat crop distributions datasets (2007 to 2011) to investigate the influence of the temporal and spatial coincidence of host and pathogen species on projected risk scores. Results were summarised using boxplots (computed from the 11-member ensemble of SCPs) to quantify uncertainty due to internal climate variation.

Projected risk of FHB spread for the 2040s and 2080s - primary inoculum is limiting

'FHB spread risk' scores (FHB risk at wheat locations weighted by the risk of primary inoculum transmission to that location) were generated using the UKCP09 SCPs for all five of the climate change scenarios and five of the rasterised wheat crop distributions datasets (2007 to 2011). For each crop distribution, wheat locations from the previous growing season (2006 to 2010, respectively) were considered as sources of primary inoculum. Model output was mapped and summarised 
by averaging over all wheat locations within crop rotations ( $n \sim 10,000$ per crop rotation) under the different climate change scenarios, in order to investigate the influence of the abundance and configuration of refugia and crop locations on projected FHB spread risk. Results were compared using boxplots (computed from the 11-member ensemble of SCPs) to quantify uncertainty due to internal climate variation.

Future agronomic scenarios

\section{Climate-change-induced shifts in crop cultivation practices}

A warmer climate and $\mathrm{CO}_{2}$ fertilization is likely to present some opportunities to increase the amount and diversity of crops grown in Scotland over the coming century (DEFRA 2012). To investigate the potential effect of a more abundant or diverse cereal population on contamination of wheat by FHB, we applied the HGCA weather based risk assessment model for FHB in wheat (primary inoculum is non-limiting) to two sets of hypothetical cultivation scenarios. In the first set of scenarios, the amount of wheat in each crop distribution (2007 to 2011) was increased by $10,20,40$, and $80 \%$, by randomly sampling wheat locations from the other crop distributions. In the second set of scenarios, we simulated maize as a previous crop for 10, 20, 40, and $80 \%$ of wheat locations in each crop distribution; i.e., a proportion of wheat grid cells in each crop distribution were randomly selected and classified as containing maize debris. Maize debris is a more potent source of inoculum of $G$. zeae than wheat debris (Kenny and Harrison 1992; West et al. 2012), therefore FHB risk scores are increased in the HGCA risk assessment model if the previous crop was grain or forage maize (Edwards 2013). This made a total of 32 cultivation scenarios ( 4 climate change scenarios $\times 4$ wheat proportions + 4 climate change scenarios $\times 4$ maize proportions).

A total of 100 simulations (iterations) were performed for each scenario, and for each iteration a different randomly selected set of wheat locations was used. FHB risk scores were averaged over all wheat locations in the five rasterised wheat crop distributions datasets, and over all iterations. Results were summarised using boxplots (computed from the 11-member ensemble of SCPs). Relative standard errors of FHB risk scores (standard error expressed as a percentage of the mean) were calculated between iterations within ensemble members, in order to assess the level to which the precision of simulation results were affected by variability in the random sampling of wheat locations, and the number of iterations performed.

\section{Climate-change-induced shifts in planting patterns}

According to the UKCP09 projections, all of Scotland is now experiencing relative sea-level rise and the rate of this rise is expected to accelerate in the future (Lowe et al. 2009). To investigate the potential effect of shifting wheat production further inland on the risk of FHB, we applied the HGCA weather based risk assessment model for FHB in wheat to four hypothetical planting scenarios: crop locations were shifted 1, 2, 4, and $8 \mathrm{~km}$ inland. FHB risk scores were generated assuming a distant, worst-case scenario (using the UKCP09 high emissions scenario for a 2080 s time-slice) for five of the rasterised wheat crop distribution datasets (2007 to 2011). Model output was summarised by averaging over all wheat locations, and results were compared using boxplots (computed from the 11-member ensemble of $\mathrm{SCPs}$ ) to quantify uncertainty due to internal climate variation.

\section{Results}

Crop distribution data

There was little inter-year variability in the spatial coverage of wheat crops in Scotland (Fig. 1). This is because the percentage of prime quality agricultural land is small in Scotland, and the majority of this limited to the eastern seaboard of the country. This means that wheat production tends to cluster geographically and fields are not rotated far from the previous year's crop, which increases the risk of inoculum transfer.

Weather data for climate change scenarios

Although future weather varied depending on which of many scenarios were used, a warmer climate with drier summers and wetter winters is expected for Scotland (Fig. 2). For instance, in the main cropping area of the eastern seaboard of Scotland under the low $\mathrm{CO}_{2} 2080 \mathrm{~s}$ scenario, the projected changes in summer and winter mean temperatures range from +1.4 to $+3.1^{\circ} \mathrm{C}$ (across the 11 -member ensemble) and +1.3 to $+2.9^{\circ} \mathrm{C}$, 


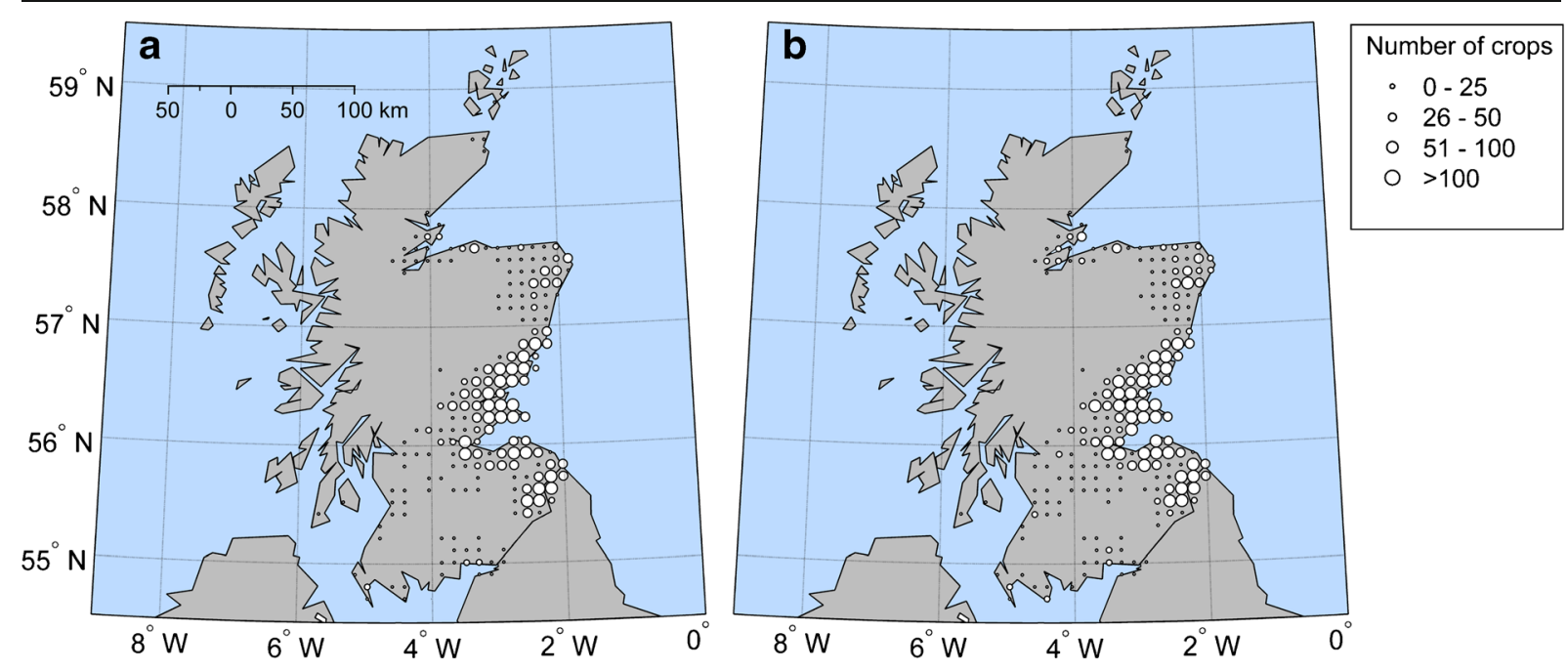

Fig. 1 Example maps showing the distribution of wheat production areas in Scotland in $\mathbf{a} 2010$ and $\mathbf{b} 2011$. Data have been aggregated to a 5 arcminute (approximately $10 \times 10 \mathrm{~km}$ ) grid for illustrative purposes

respectively; the projected changes in summer and winter mean rainfall range from -22.9 to $+2.9 \%$ and +0.4 to $+19.5 \%$, respectively; and the projected changes in summer and winter mean wind speeds range from -0.27 to $-0.004 \mathrm{~m} \mathrm{~s}^{-1}$ and -0.42 to $-0.002 \mathrm{~m} \mathrm{~s}^{-1}$, respectively. In the eastern seaboard of Scotland under the high $\mathrm{CO}_{2}$ 2080s scenario, the projected changes in summer and winter mean temperatures range from +3.6 to $+7.1{ }^{\circ} \mathrm{C}$ (Fig. 2a) and +3.1 to $+6.2{ }^{\circ} \mathrm{C}$ (Fig. 2b), respectively; the projected changes in summer and winter mean rainfall range from -44.2 to $-3.5 \%$ (Fig. 2c) and -2.4 to $+37.2 \%$ (Fig. $2 \mathrm{~d}$ ), respectively; and the projected changes in summer and winter mean wind speeds range from to -0.41 to $-0.02 \mathrm{~m} \mathrm{~s}^{-1}$ (Fig. 2e) and -0.61 to $+0.1 \mathrm{~m} \mathrm{~s}^{-1}$ (Fig. 2f), respectively.

The projected climate trends were compatible with a review of recent historical climate trends in Scotland (Barnett et al. 2006). Their analysis showed that summer mean temperatures in the east of Scotland increased by $1.12{ }^{\circ} \mathrm{C}$ between 1961 and 2004, and winter temperatures increased by $1.39^{\circ} \mathrm{C}$. Summer rainfall in the east of Scotland decreased by $18.9 \%$ and winter rainfall increased by $18.4 \%$.

Projected risk of FHB for the 2040s

and 2080 s - primary inoculum is non-limiting

The projections for anthesis dates suggest that as the weather in Scotland changes, dates of anthesis will get progressively earlier (Fig. 3a). Anthesis dates are projected to be earlier in the high $\mathrm{CO}_{2}$ scenarios when compared to the corresponding low $\mathrm{CO}_{2}$ scenarios: c. 15 June to 1 July for the Lo 2040 scenario (the range across the 11 member SCP ensemble of the mean value for Scotland), c. 30 May to 26 June for the Hi 2040 scenario, c. 10 June to 28 June for the Lo 2080 scenario, and c. 9 May to 11 June for the Hi 2080 scenario. As summer precipitation is predicted to decrease, total precipitation during flowering decreases (Fig. 3b). The onset of grain ripening is also projected to be earlier in the high $\mathrm{CO}_{2}$ scenarios when compared to the corresponding low $\mathrm{CO}_{2}$ scenarios (Fig. 3c): c. 4 Aug to 25 Aug for the Lo 2040 scenario, c. 18 July to 18 Aug for the Hi 2040 scenario, c. 29 July to 21 Aug for the Lo 2080 scenario, and c. 26 June to 31 July for the Hi 2080 scenario. As summer precipitation is predicted to decrease, total precipitation during the ripening period also decreases (Fig. 3d). Risk of FHB contamination of wheat is assessed on the basis of total rainfall accumulated during these two key periods of wheat growth, thus there was a marked decrease in projected FHB risk scores (Fig. 3e). There is notable geographic variability in the response of various components of FHB risk to climate change, with final FHB risk scores differing by as much as $25 \%$ among national, regional and crop averages (Fig. 3).

These projected trends in the crop life cycle were compatible with historical records. The Scottish Government gathers crop intelligence from commercial crops in Scotland as part of its Crop Health Advisory Activity. This information shows that crop development has changed, and at certain growth periods wheat crops in the east of Scotland are 2-3 weeks earlier compared 

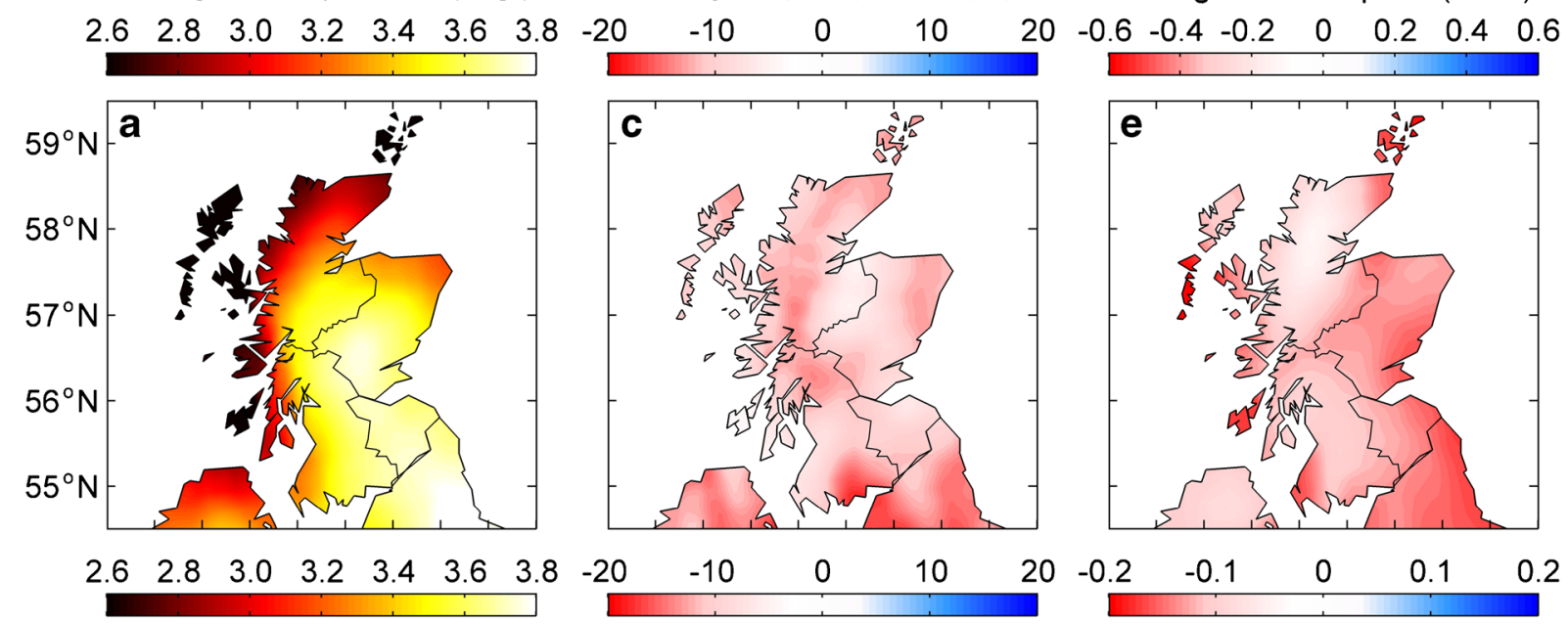

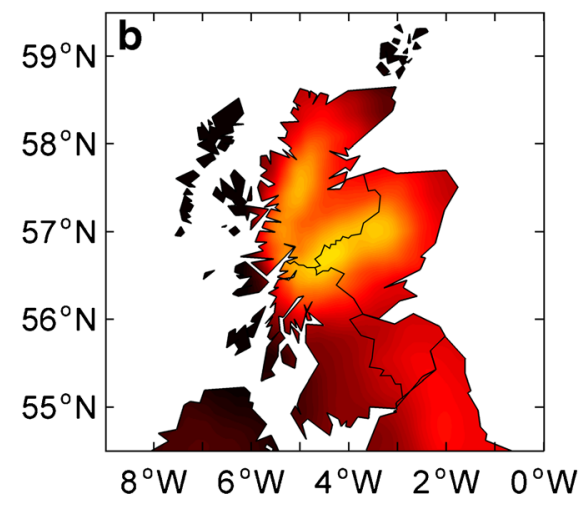

Fig. 2 Example from the 1st member of the UKCP09 SCP ensemble of changes in a summer (June, July, August) temperature, b winter (December, January, February) temperature, c summer precipitation, $\mathbf{d}$ winter precipitation, e summer wind speed, and $\mathbf{f}$ winter wind speed for a 2070-2099 time-slice taken relative

to 30 years ago. These data can be accessed at: http:// dbserver.sac.ac.uk/ adoptacrop/. Summer mean temperatures have increased by approximately $0.8{ }^{\circ} \mathrm{C}$ in the east of Scotland over this period (Barnett et al. 2006), so the projected changes for anthesis and ripening periods in 2040 and 2080 seem both in the right direction and order of magnitude.

Projected risk of FHB spread for the 2040s and 2080 s - primary inoculum is limiting

The effect of inter-crop variation on the risk of primary inoculum transmission, $I(-)$, was apparent but not pronounced (Fig. 4). This is due to the aforementioned lack of inter-year variability in the spatial coverage of wheat crops in Scotland, and the capacity of ascospores for long-distance transport. Nonetheless, when risk scores were weighted by $I$, the resultant 'FHB spread risk' scores varied by as much as $12 \%$ between crop distributions (Fig. 5). The trend of decreasing spread risk with increasing time and emissions mirrored that of the unweighted FHB risk scores in the previous section (Fig. 3e).

Future agronomic scenarios

\section{Climate-change-induced shifts in crop cultivation practices}

Projections show that wheat production could be increased by up to $40 \%$ in the 2040 s and $80 \%$ in the 2080 s without increasing the risk of FHB contamination 

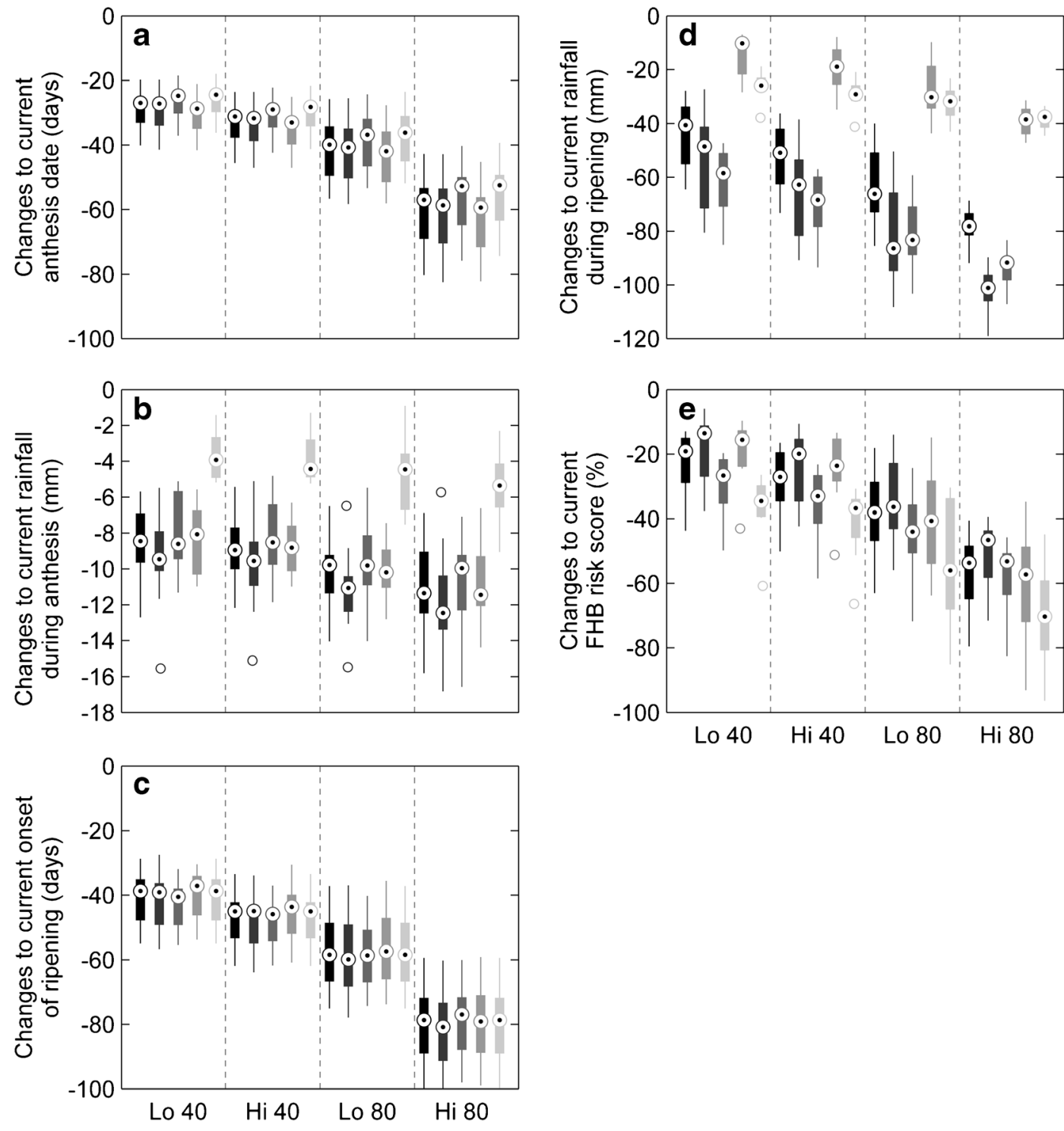

\section{UKCP09 emissions scenario}

Fig. 3 Projected change in component risk factors of the HGCA weather based risk assessment model for Fusarium head blight in wheat under future climates: a time to the onset of anthesis, $\mathbf{b}$ total rainfall accumulation during anthesis, $\mathbf{c}$ time to the onset of grain ripening, $\mathbf{d}$ total rainfall accumulation during ripening, and $\mathbf{e}$ final risk score. The climate change scenarios are low $\mathrm{CO}_{2}(\mathrm{lo})$ and high $\mathrm{CO}_{2}$ (hi) for the 2040s and 2080s and projected changes are expressed relative to the 1961-1991 baseline climatology to show

of wheat (for the case where primary inoculum is nonlimiting) above baseline (current) levels (Fig. 6a). The effect of the amount of additional wheat on FHB risk diminished with increasing time and emissions, due to the trend of decreasing FHB risk with increasing time and $\mathrm{CO}_{2}$ emissions. the proportional response. Within each climate change scenario, boxplots show uncertainty due to internal climate variation for risk factors averaged over: Scotland; the northern, western, and eastern Scotland climate regions; and all wheat production areas, respectively (boxplots ranging from black to light grey). Boxes extend from first to third quartile, medians are marked in each box, whiskers cover the $95 \%$ probability interval, and circular markers outside of this range are extreme values

Similarly, projections show that maize could be introduced into crop rotations at up to $40 \%$ of current wheat production levels in the 2040s, and $80 \%$ in the 2080s without increasing the risk of FHB contamination of wheat above baseline (current) levels (Fig. 6b). The additional FHB risk imposed by maize remained 


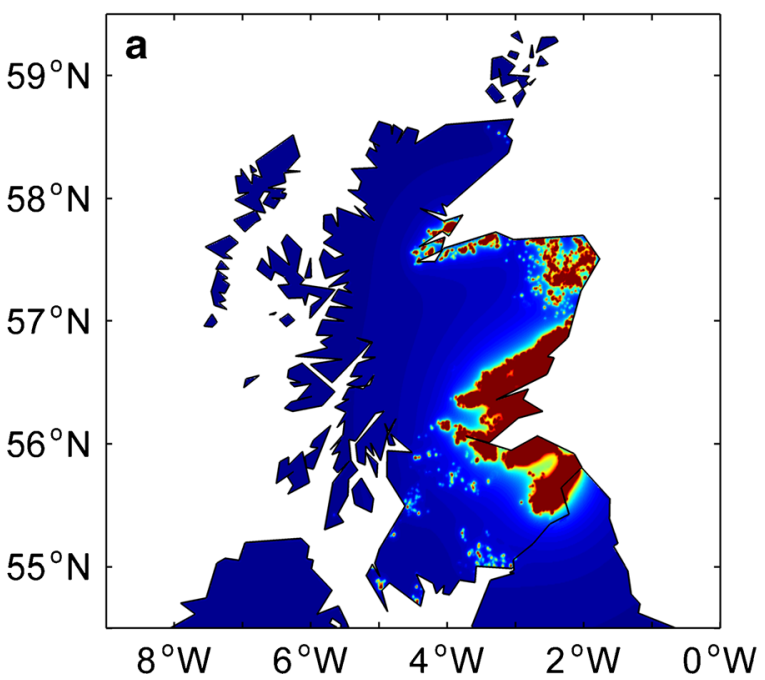

Fig. 4 Example maps showing the risk of primary inoculum transmission, $I$, from crop debris using baseline climatology and wheat production areas in Scotland in (a) 2010 and (b) 2011 as primary inoculum sources. For illustrative purposes, maps were

constant with increasing time and $\mathrm{CO}_{2}$ emissions, as the potency of maize as a risk factor in the HGCA weather based risk assessment model for FHB in wheat is fixed.

Relative standard errors between iterations (describing the influence of variability in the random sampling

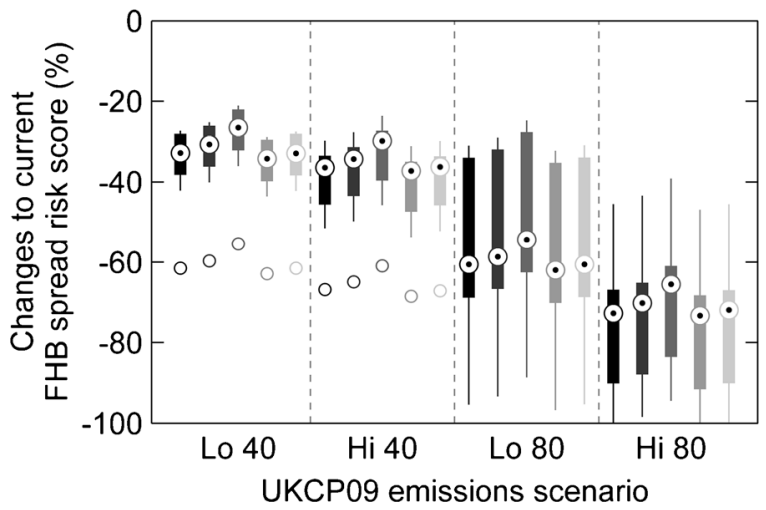

Fig. 5 Projected change in the risk of spread of Fusarium head blight from refugia to wheat crops, and subsequent development, in Scotland. The climate change scenarios are low $\mathrm{CO}_{2}$ (lo) and high $\mathrm{CO}_{2}$ (hi) for the 2040s and 2080s and projected changes are expressed relative to the 1961-1991 baseline climatology to show the proportional response. Within each climate change scenario, boxplots shows uncertainty due to internal climate variation for risk scores averaged over all wheat locations within individual crop distributions (boxplots ranging from black to light grey are for 2007 to 2011). Boxes extend from first to third quartile, medians are marked in each box, whiskers cover the $95 \%$ probability interval, and circular markers outside of this range are extreme values

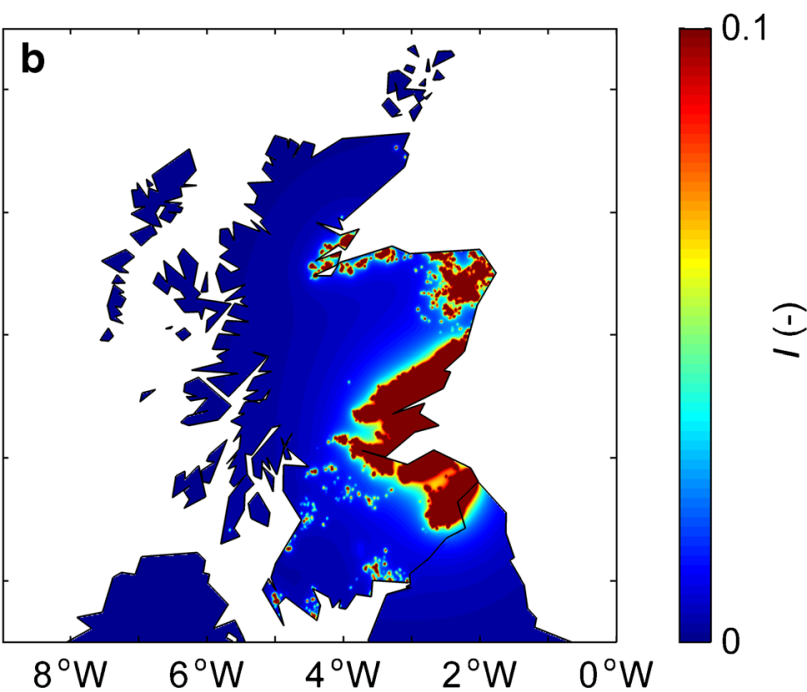

produced assuming a uniformly suitable landscape for ascospore deposition; i.e., maps show risk of inoculum transmission from specific sources of crop debris to all land pixels. Figure 1 provides maps of the crop distributions

of wheat locations on projected FHB risk) ranged from 0.02 to $0.7 \%$, with a mean value of $0.3 \%$. The level of replication was therefore deemed adequate for reducing noise in simulation outcomes to a level that did not obscure emergent patterns.

\section{Climate-change-induced shifts in planting patterns}

Shifting wheat production away from coastal areas had a negligible effect on the risk of FHB (Fig. 7). This suggests that rising sea levels would have a limited impact on wheat production, provided suitable land for cultivation could be found further inland.

\section{Discussion}

The results suggest that climate change will cause dates of wheat anthesis and ripening to occur earlier in Scotland. This means that the critical time periods when rainfall favours FHB infection and saprophytic growth will be earlier in the year, when weather is projected to be drier than the baseline climatology. Consequently, the risk of wheat FHB epidemics is expected to decrease in Scotland in the future. This suggests that not only will there be a decrease in yield losses due to grain shrivelling, but also a decrease in the risk of mycotoxin contamination of grain. Improved control of FHB might 


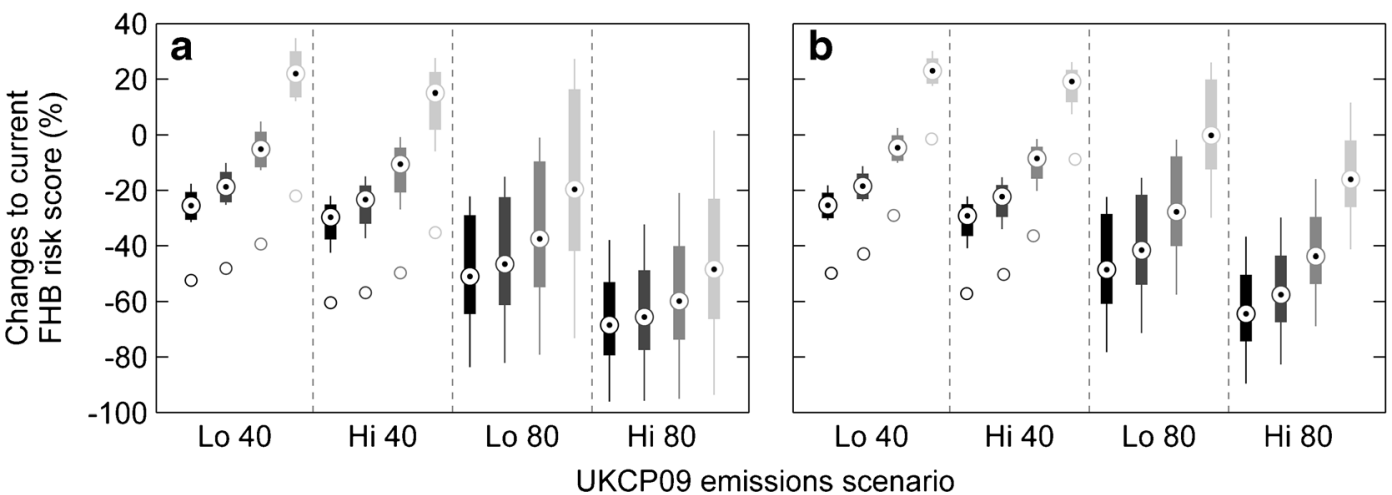

Fig. 6 Projected change in the risk of contamination of wheat by Fusarium head blight in Scotland resulting from a increased wheat production, and $\mathbf{b}$ introduction of maize into crop rotations. The climate change scenarios are low $\mathrm{CO}_{2}$ (lo) and high $\mathrm{CO}_{2}$ (hi) for the 2040s and 2080s and projected changes are expressed relative to the 1961-1991 baseline climatology to show the proportional response. Within each climate change scenario, individual

therefore not be as high a priority for future food security preparedness in Scotland as had hitherto been assumed. This has important consequences for how agricultural adaptation to climate change is approached in Scotland. Results indicate that opportunities exist for increased cultivation of wheat and/or crops considered as potent sources of Fusarium or Gibberella inoculum, such as grain maize, and for significant movement of wheat production away from areas such as coasts vulnerable to sea-level rise, with little additional risk of FHB.

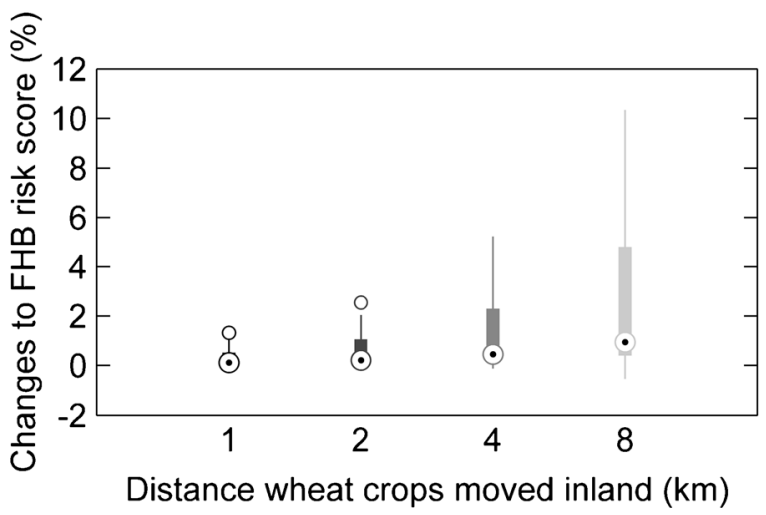

Fig. 7 Projected change in the risk of contamination of wheat by Fusarium head blight in Scotland after shifting crop locations further inland. A worst-case scenario was assumed (high emission scenario for a 2080s timeslice), and individual boxplots show uncertainty due to internal climate variation for risk scores averaged over all wheat locations and crop distributions. Boxes extend from first to third quartile, medians are marked in each box, whiskers cover the $95 \%$ probability interval, and circular markers outside of this range are extreme values boxplots show uncertainty due to internal climate variation for risk scores averaged over all wheat locations and crop distributions for a $10,20,40$, and $80 \%$ increase in the amount of wheat or maize, respectively (boxplots ranging from black to light grey). Boxes extend from first to third quartile, medians are marked in each box, whiskers cover the $95 \%$ probability interval, and circular markers outside of this range are extreme values

This work demonstrates that it is relatively simple and informative to combine multiple environmental datasets to add spatial context into risk assessments for crop diseases under future climates. The large difference in results at the national-, regional-, and (wheat) population-scale (Fig. 3e) highlights the need to consider crop locations in risk projections, and suggests caution in interpreting studies in which it is not a major feature of the study design. For example, Madgwick et al. (2011) predict a $333 \%$ increase in FHB incidence in Scotland by the 2050s on the basis of risk projections computed at two locations near the coast in the Eastern Scotland climate region. Scotland is well-known, however, for the geographic variability of its weather and the UKCP09 SCPs predict large variation in weather variables both within and between climate regions (Fig. 2). Consequently, crop location exerted a large influence on FHB risk in the current study (Fig. 3e). Importantly, our methodology does not simply inflate the predicted risk of disease in areas where suitable weather for infection and the presence of host plants at a susceptible growth stage (i.e., at flowering or grain ripening) coincide. Instead, it makes an additional prediction that accounts for the role of landscape connectivity in crop pathogen invasions; i.e., the coincidence of inoculum, suitable weather for infection, and the presence of host plants at a susceptible growth stage. This was facilitated through the use of an atmospheric dispersion model from the meteorological sciences to compute transportation of ascospores from over-wintering refugia to crop locations. Consequently, 
we found that risk scores for potential spread of FHB in wheat varied between crop rotations. The practical importance of this inter-crop variation in FHB spread risk may be significant for future food security in areas where the Fusarium and Gibberella mycotoxin food hazard is expected to increase. The influence of crop distribution suggests potential for the design of FHBsuppressive landscapes, where a more strategic approach to the introduction of new crops and cropping sequences is adopted. Alternatively, recent ecological theory suggests that the scale of crop heterogeneity in commercial production areas can be tailored to minimise or negate the spread of specific pests and pathogens (Skelsey et al. 2013a, b; Skelsey and Newton 2014), therefore it may be advantageous to modify field size or separation distances wherever possible.

A number of methodological limitations necessitate caution in interpreting the findings of this study. Most General Circulation Models (climate models) make projections at a relatively coarse resolution and cannot represent the fine scale detail that characterises the climate in many regions of the world. UKCP09 probabilistic projections are designed to sample much of the uncertainty introduced by deficiencies in climate models by the use of perturbed physics and multi-model ensembles, but given the highly complex orography, heterogeneous land surface cover and coastlines of Scotland, some uncertainty remains as to the accuracy of projected climate variables. We did not consider the effect of climate on the decomposition rate of crop debris, which may be enhanced under the warmer, wetter winter conditions expected for Scotland, resulting in less primary inoculum. This could be useful in the future to better quantify inoculum pressure. Regarding the response of FHB to climate, the adaptive potential of various species within the FHB pathogen complex was not incorporated into the risk assessment, and this may prove to be an important predictor of the magnitude of climate change effects on FHB epidemics and associated mycotoxin hazard. Although FHB risk is expected to decline in Scotland, the emergence of new pathogen genotypes that are adapted to drier conditions or that can cause infections outside of the current envelope of environmental conditions could confound projections. Nonetheless, warmer, drier summers are the likely climate scenario for the arable-growing region of Scotland, and as similar current climates such as southern-eastern England sites are normally dominated by G. zeae, then it is likely to continue to dominate.
G. zeae is believed to have been introduced to the UK and has become a common and often dominant component of the FHB complex since 1997, almost certainly due to the increase in maize production in southern England (www.hgca.com/media/243889/Paul Nicholson.pdf). Maize is a dominant reservoir of Fusarium and Gibberella inoculum but this observation not only provided the rationale for simulating the effects of increased production in Scotland, it also illustrates how risk can be affected by indirect effects of climate and market-driven changes to cropping practices. However, a previous maize crop increases risk in the HGCA risk assessment by an expert opinion-derived factor rather than specific data-driven experimental evidence. It would prove too difficult to provide such data applicable to the range of geographic and agronomic environments being addressed but further validation of the risk value would add confidence to these predictions. Should maize production have favoured Microdochium species then we might have a reduced mycotoxin risk, as $M$. nivale and M. majus produce no known mycotoxins (Edwards 2007). Thus there is an additional degree of uncertainty about mycotoxin risk above that of projected FHB risk. Inoculum pressure and composition will correlatively but differentially affect these two risks and be driven not only by weather and climate change, but also by competition with other pathogens (Xu et al. 2007a, b), fungicide applications (Pirgozliev et al. 2002), and cropping practices (Brennan et al. 2007; Landschoot et al. 2013; Leoni et al. 2013). The latter may be influenced by markets and policy that may or may not be affected by climate change. This uncertainty would be reduced by characterising the environmental interactions of likely component species of the FHB-complex with respect to the main climate change parameters, and by improving the performance and parsimony of models relating the probability of mycotoxin accumulation to weather predictors (Xu et al. 2013). Despite much research, predictive power for infection and FHB development, precursors for DON in a wheat spike, are still not that high (Moschini and Fortugno 1996; Moschini et al. 2001; De Wolf et al. 2003; Xu et al. 2007b; Shah et al. 2013). There is also still some uncertainty about the nature of the moisture and rainfall effects post-anthesis on DON production given the differences in reported results (Culler et al. 2007; Cowger et al. 2009).

In this study we consider the temporal and spatial coincidence of wheat, Fusarium and Gibberella species 
under various climate change scenarios to project the future environmental and geographic risks of wheat FHB in Scotland. This work demonstrates the importance of spatial context in climate change risk assessments for plant disease epidemics, and presents a novel approach for including regional inoculum dispersal as a spatial risk factor. We identify gaps in our knowledge with respect to FHB-complex species differences in response to climate change that would improve confidence in our predictions. Nevertheless, the results provide useful information to guide government and industry strategies for agricultural adaptation to climate change, and the methodology developed in this study is extendable to other pathosystems characterised by airborne inoculum.

Acknowledgments The authors thank Fiona Burnett at SRUC for her very helpful advice, enthusiasm and comments on this work. We are grateful for financial support for this work in part from the Rural and Environment Science and Analytical Services (RESAS) Division of the Scottish Government (2011-2016) under its Environmental Change and Food, Land and People Research Programmes.

Open Access This article is distributed under the terms of the Creative Commons Attribution License which permits any use, distribution, and reproduction in any medium, provided the original author(s) and the source are credited.

\section{References}

Barnett, C., Hossell, J., Perry, M., Procter, C., Hughes, G. (2006). A handbook of climate trends across Scotland. In SNIFFER project CCO3, Scotland \& Northern Ireland Forum for Environmental Research, Edinburgh, UK (pp. 66).

Beddington, J. (2010). Food security: contributions from science to a new and greener revolution. Philosophical Transactions of the Royal Society, B: Biological Sciences, 365(1537), $61-71$.

Brennan, J., Leonard, G., Fagan, B., Cooke, B., Ritieni, A., Ferracane, R., et al. (2007). Comparison of commercial European wheat cultivars to Fusarium infection of head and seedling tissue. Plant Pathology, 56(1), 55-64.

Campbell, H., Choo, T. M., Vigier, B., \& Underhill, L. (2002). Comparison of mycotoxin profiles among cereal samples from eastern Canada. Canadian Journal of Botany, 80(5), 526-532.

Chakraborty, S. (2005). Potential impact of climate change on plant-pathogen interactions. Australasian Plant Pathology, 34(4), 443-448.

Chakraborty, S., \& Newton, A. C. (2011). Climate change, plant diseases and food security. Plant Pathology, 60, 2-14.

Cowger, C., Patton-Özkurt, J., Brown-Guedira, G., \& Perugini, L. (2009). Post-anthesis moisture increased Fusarium head blight and deoxynivalenol levels in North Carolina winter wheat. Phytopathology, 99(4), 320-327.

Culler, M., Miller-Garvin, J., \& Dill-Macky, R. (2007). Effect of extended irrigation and host resistance on deoxynivalenol accumulation in Fusarium-infected wheat. Plant Disease, 91(11), 1464-1472.

De Wolf, E., Madden, L., \& Lipps, P. (2003). Risk assessment models for wheat Fusarium head blight epidemics based on within-season weather data. Phytopathology, 93(4), 428-435.

DEFRA. (2012). UK climate change risk assessment. London: The Stationery Office.

Desjardins, A., \& Proctor, R. (2007). Molecular biology of Fusarium mycotoxins. International Journal of Food Microbiology, 119(1), 47-50.

Edwards, S. (2007). Investigation of Fusarium mycotoxins in UK barley and oat production. HGCA Project Report No. 415. Caledonia House: Home Grown Cereals Authority.

Edwards, S. (2011). Improving risk assessment to minimise Fusarium mycotoxins in harvested wheat grain. HGCA Project Report No. 477. Caledonia House: Home Grown Cereals Authority.

Edwards, S. (2012). Improving risk assessment to minimize Fusarium mycotoxins in harvested oats and malting barley. HGCA Project Report No. 500. Caledonia House: Home Grown Cereals Authority.

Edwards, S. (2013). HGCA risk assessment for fusarium mycotoxins in wheat. Topic Sheet 121 (Topic sheet 121). Caledonia House: Home Grown Cereals Authority.

Fernandes, J. M., Cunha, G., Del Ponte, E., Pavan, W., Pires, J., Baethgen, W., et al. (2004). Modelling Fusarium head blight in wheat under climate change using linked process-based models. In Proc. 2nd International Symposium on Fusarium Head Blight (pp. 441-444). East Lansing, Michigan: Michigan State University.

Francl, L., Shaner, G., Bergstrom, G., Gilbert, J., Pedersen, W., Dill-Macky, R., et al. (1999). Daily inoculum levels of Gibberella zeae on wheat spikes. Plant Disease, 83(7), 662-666.

Garrett, K., Dendy, S., Frank, E., Rouse, M., \& Travers, S. (2006). Climate change effects on plant disease: genomes to ecosystems. Annual Review of Phytopathology, 44, 489-509.

Garrett, K., Forbes, G., Savary, S., Skelsey, P., Sparks, A., Valdivia, C., et al. (2011). Complexity in climate-change impacts: an analytical framework for effects mediated by plant disease. Plant Pathology, 60(1), 15-30.

Gouache, D., Roche, R., Pieri, P., Bancal, M. (2007). Evolution of some pathosystems on wheat and vines, section B5. Climate change, agriculture and forests in France: Simulations of the impacts on the main species: The Green Book of the CLIM ATOR project, 2010, 336.

Hay, R. K. M., Russell, G., \& Edwards, T. E. (2000). Crop production in the east of Scotland. Edinburgh: Scottish Agricultural Science Agency.

HGCA. (2008). The wheat growth guide. Caledonia House: Home Grown Cereals Authority.

HGCA. (2012). Improved modelling of Fusarium to aid mycotoxin prediction in UK wheat. Annual project report 2012. Caledonia House: Home Grown Cereals Authority.

Hooker, D., Schaafsma, A., \& Tamburic-Ilincic, L. (2002). Using weather variables pre-and post-heading to predict 
deoxynivalenol content in winter wheat. Plant Disease, 86(6), 611-619.

Jennings, P., Coates, M., Walsh, K., Turner, J., \& Nicholson, P. (2004). Determination of deoxynivalenol-and nivalenol-producing chemotypes of Fusarium graminearum isolated from wheat crops in England and Wales. Plant Pathology, 53(5), 643-652.

Jones, R., \& Mirocha, C. (1999). Quality parameters in small grains from Minnesota affected by Fusarium head blight. Plant Disease, 83(6), 506-511.

Kenny, G., \& Harrison, P. (1992). Thermal and moisture limits of grain maize in Europe: model testing and sensitivity to climate change. Climate Research, 2(2), 113-129.

Kerr, A., Shackley, S., Milne, R., \& Allen, S. (1999). Climate change: Scottish implications scoping study. Edinburgh: The Scottish Executive Central Research Unit.

Khonga, E., \& Sutton, J. (1988). Inoculum production and survival of Gibberella zeae in maize and wheat residues. Canadian Journal of Plant Pathology, 10(3), 232-239.

Kriss, A. B., Paul, P. A., Xu, X., Nicholson, P., Doohan, F. M., Hornok, L., et al. (2012). Quantification of the relationship between the environment and Fusarium head blight, Fusarium pathogen density, and mycotoxins in winter wheat in Europe. European Journal of Plant Pathology, 133(4), 975-993.

Landschoot, S., Waegeman, W., Audenaert, K., Vandepitte, J., Haesaert, G., \& De Baets, B. (2012). Toward a reliable evaluation of forecasting systems for plant diseases: a case study using Fusarium head blight of wheat. Plant Disease, 96(6), 889-896.

Landschoot, S., Waegeman, W., Audenaert, K., Van Damme, P., Vandepitte, J., De Baets, B., et al. (2013). A field-specific web tool for the prediction of Fusarium head blight and deoxynivalenol content in Belgium. Computers and Electronics in Agriculture, 93, 140-148.

Langevin, F., Eudes, F., \& Comeau, A. (2004). Effect of trichothecenes produced by Fusarium graminearum during Fusarium head blight development in six cereal species. European Journal of Plant Pathology, 110(7), 735-746.

Leoni, C., de Vries, M., ter Braak, C. J., van Bruggen, A. H., \& Rossing, W. A. (2013). Fusarium oxysporum f. sp. cepae dynamics: in-plant multiplication and crop sequence simulations. European Journal of Plant Pathology, 137(3), 545561.

Lowe, J., Howard, T., Pardaens, A., Tinker, J., Holt, J., Wakelin, S., et al. (2009). UK Climate Projections science report: Marine and coastal projections. Exeter, UK.

Madgwick, J. W., West, J. S., White, R. P., Semenov, M. A., Townsend, J. A., Turner, J. A., et al. (2011). Impacts of climate change on wheat anthesis and fusarium ear blight in the UK. European Journal of Plant Pathology, 130(1), 117-131.

Maldonado-Ramírez, S. L. (2001). Aerobiology of the wheat scab fungus, Gibberella Zeae: Discharge, atmospheric dispersal, and depostition of ascospores. New York: Cornell University.

Maldonado-Ramirez, S. L., Schmale, D. G., III, Shields, E. J., \& Bergstrom, G. C. (2005). The relative abundance of viable spores of Gibberella zeae in the planetary boundary layer suggests the role of long-distance transport in regional epidemics of Fusarium head blight. Agricultural and Forest Meteorology, 132(1), 20-27.
McMullen, M., Jones, R., \& Gallenberg, D. (1997). Scab of wheat and barley: a re-emerging disease of devastating impact. Plant Disease, 81(12), 1340-1348.

Metz, B. (2007). Climate Change 2007-Mitigation of Climate Change: Working Group III Contribution to the Fourth Assessment Report of the IPCC (Vol. 4). Cambridge University Press.

Miedaner, T., Cumagun, C., \& Chakraborty, S. (2008). Population genetics of three important head blight pathogens Fusarium graminearum, F. pseudograminearum and F. culmorum. Journal of Phytopathology, 156(3), 129-139.

Miraglia, M., Marvin, H., Kleter, G., Battilani, P., Brera, C., Coni, E., et al. (2009). Climate change and food safety: an emerging issue with special focus on Europe. Food and Chemical Toxicology, 47(5), 1009-1021.

Moschini, R. C., \& Fortugno, C. (1996). Predicting wheat head blight incidence using models based on meteorological factors in Pergamino, Argentina. European Journal of Plant Pathology, 102(3), 211-218.

Moschini, R. C., Pioli, R., Carmona, M., \& Sacchi, O. (2001). Empirical predictions of wheat head blight in the northern Argentinean Pampas region. Crop Science, 41(5), 15411545. doi:10.2135/cropsci2001.4151541x.

Parry, D., Jenkinson, P., \& McLeod, L. (1995). Fusarium ear blight (scab) in small grain cereals - a review. Plant Pathology, 44(2), 207-238.

Pirgozliev, S., Edwards, S., Hare, M., \& Jenkinson, P. (2002). Effect of dose rate of azoxystrobin and metconazole on the development of Fusarium head blight and the accumulation of deoxynivalenol (DON) in wheat grain. European Journal of Plant Pathology, 108(5), 469-478.

Press, W. H., Teukolsky, S. A., Vetterling, W. T., \& Flannery, B. P. (1992). Numerical recipes in C. Cambridge: Cambridge University Press.

Prussin, A. J., Szanyi, N. A., Welling, P. I., Ross, S., \& Schmale, D. G., III. (2014). Estimating the production and release of ascospores from a feld-scale source of Fusarium graminearum inoculum. Plant Disease, 98(4), 497-503.

Salas, B., Steffenson, B., Casper, H., Tacke, B., Prom, L., Fetch, T., Jr., et al. (1999). Fusarium species pathogenic to barley and their associated mycotoxins. Plant Disease, 83(7), 667-674.

Schmale III, D., \& Bergstrom, G. (2003). Airborne propagules of Gibberella zeae: techniques for monitoring spore release and viability. In 2003 National Fusarium Head Blight Forum Proceedings, Bloomington, $M N$ (pp. 175).

Schmale, D. G., III, Shah, D. A., \& Bergstrom, G. C. (2005). Spatial patterns of viable spore deposition of Gibberella zeae in wheat fields. Phytopathology, 95(5), 472-479.

Scottish Government (2012). June 2012 Scottish Agricultural Census. On-line [http://www.scotland.gov.uk/Publications/ 2012/09/1148]. Accessed 12.01.2014.

Shah, D., Molineros, J., Paul, P., Willyerd, K., Madden, L., \& De Wolf, E. D. (2013). Predicting Fusarium head blight epidemics with weather-driven pre-and post-anthesis logistic regression models. Phytopathology, 103(9), 906-919.

Shaner, G. (2003). Epidemiology of Fusarium head blight of small grain cereals in North America. In K. Leonard \& W. Bushnell (Eds.), Fusarium head blight of wheat and barley (pp. 84 119). St Paul: APS Press.

Skelsey, P. (2008). Multi-scale modeling of potato late blight epidemics. Wageningen: Wageningen University. 
Skelsey, P., \& Newton, A. C. (2014). Scale-dependent assessment of relative disease resistance to plant pathogens. Agronomy, 4(2), 178-190.

Skelsey, P., Van Der Werf, W., Kessel, G., Rossing, W., \& Holtslag, A. (2007). Multi-scale modelling of infection pressure from Phytophthora infestans. EPPO Bulletin, 37(2), 313-316.

Skelsey, P., Rossing, W. A., Kessel, G. J., \& van der Werf, W. (2010). Invasion of Phytophthora infestans at the landscape level: how do spatial scale and weather modulate the consequences of spatial heterogeneity in host resistance? Phytopathology, 100(11), 1146-1161.

Skelsey, P., With, K., \& Garrett, K. (2013a). Why dispersal should be maximized at intermediate scales of heterogeneity. Theoretical Ecology, 6(2), 203-211. doi:10.1007/s12080012-0171-3.

Skelsey, P., With, K. A., \& Garrett, K. A. (2013b). Pest and disease management: why we shouldn't go against the grain. PLoS ONE, 8(9), e75892. doi:10.1371/journal.pone.0075892.

Slaiding, I., \& Byrd, N. (2013). Ensuring that UK cereals used in malting, milling and animal feed achieve food and feed safety standards. Warwickshire: Home Grown Cereals Authority.

SRUC. (2013). Crop protection report. East Edition, 13(13), 18.

Stern, N. (2007). The economics of climate change: The Stern review. Cambridge: Cambridge University Press.

Trail, F., Xu, H., Loranger, R., \& Gadoury, D. (2002). Physiological and environmental aspects of ascospore discharge in Gibberella zeae (anamorph Fusarium graminearum). Mycologia, 94(2), 181-189.
Trail, F., Gaffoor, I., \& Vogel, S. (2005). Ejection mechanics and trajectory of the ascospores of Gibberella zeae (anamorph Fuarium graminearum). Fungal Genetics and Biology, 42(6), 528-533.

Waalwijk, C., Kastelein, P., de Vries, I., Kerényi, Z., van der Lee, T., Hesselink, T., et al. (2003). Major changes in Fusarium spp. in wheat in the Netherlands. European Journal of Plant Pathology, 109(7), 743-754.

West, J. S., Holdgate, S., Townsend, J. A., Edwards, S. G., Jennings, P., \& Fitt, B. D. (2012). Impacts of changing climate and agronomic factors on fusarium ear blight of wheat in the UK. Fungal Ecology, 5(1), 53-61.

Xu, X.-M., Monger, W., Ritieni, A., \& Nicholson, P. (2007a). Effect of temperature and duration of wetness during initial infection periods on disease development, fungal biomass and mycotoxin concentrations on wheat inoculated with single, or combinations of, Fusarium species. Plant Pathology, 56(6), 943-956.

Xu, X., Nicholson, P., \& Ritieni, A. (2007b). Effects of fungal interactions among Fusarium head blight pathogens on disease development and mycotoxin accumulation. International Journal of Food Microbiology, 119(1), 67-71.

Xu, X., Madden, L. V., \& Edwards, S. (2013). Modeling the effects of environmental conditions on HT2 and T2 toxin accumulation in field oat grains. Phytopathology, 104(1), 57-66.

Zhang, X., White, R. P., Demir, E., Jedryczka, M., Lange, R. M., Islam, M., et al. (2014). Leptosphaeria spp., phoma stem canker and potential spread of L. maculans on oilseed rape crops in China. Plant Pathology, 63(3), 598-612. 